\title{
Perfil conceitual e a escolarização do conceito de morte no ensino de Ciências
}

\section{The conceptual profile of death and its schooling process in Science teaching}

\author{
Aline Andréia Nicolli ${ }^{1}$ \\ Eduardo Fleury Mortimer ${ }^{2}$
}

\begin{abstract}
RESUMO
Apresentaremos neste artigo as etapas do trabalho de construção do modelo de perfil conceitual de morte que resultou na identificação de três zonas: naturalista, em que a morte é interpretada como resultado de processos ou propriedades biológicas; religiosa, na qual a morte é compreendida como fato ou fenômeno que resulta de uma "vontade divina", frequentemente vista como passagem para outra vida, e relacional, na qual a morte é concebida como fato ou fenômeno a ser negado, ocultado. Na sequência, abordaremos as possibilidades de escolarização do conceito de morte, no ensino de ciências, por meio do desenvolvimento de uma sequência de ensino sobre o ciclo de vida. Nessa etapa, identificaremos as diferentes zonas do perfil conceitual de morte que circularam durante a aula e o quanto o discurso da ciência pode promover alterações nos modos de falar e formas de pensar dos estudantes sobre a morte.
\end{abstract}

Palavras-chave: ensino de Ciências; perfil conceitual; ciclo de vida; morte.

\begin{abstract}
This article presents the steps that compose the construction of the conceptual profile model of death that resulted in the identification of three zones: naturalistic, in which death is interpreted as a result of biological processes or biological properties; religious, in which death is understood as a fact

${ }^{1}$ Doutora em Educação pela Universidade Federal de Minas Gerais. Professora do Centro de Educação, Letras e Artes da Universidade Federal do Acre, Brasil. E-mail: aanicolli@gmail.com.

${ }^{2}$ Doutor em Educação. Professor Titular da Faculdade de Educação da Universidade Federal de Minas Gerais. E-mail: mortimer@ufmg.br.
\end{abstract}


or phenomenon that results from a "divine will", often seen as a passage to another life, and relational, in which the death is conceived as a fact or phenomenon to be denied or hidden. Subsequently, some possibilities are proposed to turn the concept of death into a scholar subject in Science classes through the development of a teaching sequence about the life cycle. In this step, the different zones of the conceptual profile of death which circulated during the class are identified, as well as showing how much the discourse of science can promote changes in the students' ways of talking and thinking about death.

Keywords: Science teaching; conceptual profile; cycle of life; death.

\section{Introdução}

Desde criança o que se aprende nas aulas de ciências é que, se somos seres vivos, temos um ciclo de vida. No entanto, o ciclo de vida que é ensinado geralmente não considera os seguintes aspectos: (a) as possibilidades de os seres vivos não desenvolverem um ciclo de vida completo; (b) a percepção da vulnerabilidade do corpo, ou seja, do inevitável ponto final do ciclo de vida e da vida: a morte, e (c) o fato de morte ser um conceito central na existência das pessoas pela sua oposição ao conceito de vida.

Assim sendo, as experiências profissionais vivenciadas como professora formadora de professores me fazem refletir sobre as práticas pedagógicas desenvolvidas no Ensino de Ciências e sobre como elas podem contemplar a discussão de alguns conceitos polêmicos, como é o conceito de morte, considerando os modos de falar e formas de pensar dos estudantes.

Para Bakhtin (2003), o gênero de falas e a linguagem social são duas formas de estratificação da linguagem que asseguram a sua heterogeneidade. Uma linguagem social é "um discurso peculiar a um estrato específico da sociedade (linguagem profissional, linguagem de gerações etc.) dentro de um dado sistema social e num dado tempo" (HOLQUIST, 1981, p. 430). Todas as linguagens sociais são "[...] formas para conceituar o mundo em palavras, visões de mundo específicas, cada uma caracterizada por seus próprios objetos, significados e valores $[\ldots]$, como tal elas se encontram umas com as outras e coexistem na consciência das pessoas reais" (BAKHTIN, 2003, p. 291-2).

$\mathrm{Na}$ visão bakhtiniana, um falante sempre produz um enunciado usando uma linguagem social específica que dá forma ao que ele pode dizer. Por outro lado, um gênero de discurso não é uma forma de linguagem, mas uma forma 
típica de enunciado; como tal o gênero também inclui certas formas típicas de expressão que lhes são inerentes, gêneros correspondem a situações típicas da comunicação verbal, a temas típicos e, consequentemente, também a contatos particulares entre os significados das palavras e a realidade concreta, sob certas circunstâncias típicas.

Assim, enquanto uma linguagem social está relacionada com um ponto de vista específico, determinado pela posição profissional ou geracional, o gênero de discurso está relacionado ao lugar social e institucional onde o discurso é produzido.

\section{Os caminhos percorridos: aspectos metodológicos}

Realizamos uma pesquisa empírica para construir um modelo de Perfil Conceitual de Morte e identificar caracterizações do ciclo de vida, por meio da aplicação de questionários de pré e pós-teste, pois inferimos que, ao respondê-los, os sujeitos lançariam mão de uma linguagem social típica, neste caso, de estudantes e também, de certa forma, produziriam enunciados específicos da sua condição acadêmica/escolar tanto para caracterizar o ciclo de vida como para conceituar morte.

O questionário foi composto por seis situações-problema que transcreveremos a seguir: (1) Para você o que é MORTE?; (2) Durante uma aula, um aluno faz a seguinte pergunta ao professor: Os organismos vivos e não vivos são constituídos por várias substâncias, compostas pelos mesmos elementos químicos. Sendo assim, por que os organismos vivos, diferente dos não vivos, MORREM? Como você responderia essa questão?; (3) Imagine a seguinte situação: alguém pede para você expressar sua opinião sobre de que forma a MORTE pode se efetivar e/ou se manifestar em um determinado ser que até então era vivo. Como você responderia a questão?; (4) Para muitas pessoas a MORTE é resultado da "vontade divina". Qual sua opinião sobre o exposto?; (5) Quais considerações você teceria, sobre a MORTE, diante de cada uma das notícias: (5a) Faleceu a avó, de 92 anos, de seu/sua melhor amigo(a); (5b) Faleceu o pai, de 55 anos, de seu/sua melhor amigo(a).; (5c) Faleceu o irmão, de 26 anos, do seu/sua melhor amigo(a) e (6) Considerando o que você aprendeu, no ensino fundamental, caracterize CICLO DE VIDA.

A primeira questão era aberta e tinha o objetivo de suscitar uma diversidade de respostas e promover a identificação de várias zonas do Perfil Conceitual de Morte. As questões 2 a 5 objetivavam fazer o sujeito refletir, respectivamente, 
sobre a condição mortal dos vivos; sobre formas pelas quais a morte pode se manifestar; sobre a concepção "divina da morte" e sobre a morte em três situações específicas que hipoteticamente relatavam a morte de diferentes sujeitos, com diferentes idades e diferentes papéis sociais. A questão 6 objetivava permitir a identificação das caracterizações comumente atribuídas ao ciclo de vida.

Constituíram-se como etapas do trabalho, que buscou identificar as zonas para o modelo de perfil conceitual de morte, a construção histórica do conceito de morte, considerando-se a Biologia, Medicina, Filosofia, Sociologia, Psicologia e Psicanálise, e a identificação das zonas do perfil por meio do jogo dialógico entre os elementos teóricos e os dados empíricos coletados com 321 estudantes dos cursos de graduação em Ciências Biológicas, Medicina, Ciências Sociais e Pedagogia de uma Universidade Pública Federal e 40 estudantes de sétima série (oitavo ano) do ensino fundamental ${ }^{3}$ de uma Escola Pública Estadual, instituições localizadas em Rio Branco - Acre.

\section{Dos aspectos teóricos aos dados coletados: a definição das zonas}

Segundo Mortimer (1996, 2001), as zonas de um determinado perfil conceitual são determinadas por compromissos epistemológicos e ontológicos e são construídas em um processo dinâmico e complexo de interação, no qual novos significados são internalizados. Assim, apesar de cada sujeito possuir seu perfil conceitual em relação a determinado conceito, as zonas que constituem esse perfil são as mesmas em um dado contexto sociocultural, visto que elas são formas de pensar construídas nas interações sociais. O que varia de um sujeito para outro é a importância relativa de cada zona em suas experiências de vida, o que refletirá em seu pensamento e na sua comunicação.

Se considerarmos que a noção de perfil conceitual estabelecida por Mortimer $(1996,2001)$ indica que cada conceito pode apresentar múltiplos significados, que se encontram dispersos em zonas distintas e, por isso, abarcam uma

${ }^{3}$ A escolha dos sujeitos considerou os seguintes critérios: (1) no caso dos estudantes de graduação: investigar dois cursos das áreas Biológicas e Saúde (Ciências Biológicas e Medicina), sendo um responsável pela formação de Licenciados e o outro pela formação de Bacharéis e dois cursos das áreas de Humanas (Ciências Sociais e Pedagogia), obedecendo também ao critério referente à formação de Licenciados, no primeiro caso, e Bacharéis, no segundo, e (2) no caso dos estudantes de Ensino Fundamental: aplicação de questionários em duas turmas de alunos de $7 .^{\mathrm{a}}$ série (oitavo ano) do Ensino Fundamental. Esses questionários foram aplicados antes e depois da abordagem pedagógica da unidade Ciclo de Vida, para permitir o estudo da evolução de seus Perfis Conceituais. 
diversidade de significados cotidianos e científicos, podemos dizer que o estudo da morte justifica-se por se tratar de um conceito polissêmico, o que permitiu a identificação de diferentes áreas de estabilidade conceitual dispersas em zonas, e por ser um conceito usado tanto na linguagem cotidiana quanto na linguagem científica em diversas áreas de conhecimento. Por isso, não iremos apresentar um conceito ou uma ideia singular que atenda à ânsia humana de encontrar uma solução para os conflitos e medos referentes à morte, mas, sim, três formas de pensar e falar sobre a morte que emergiram da identificação das categorias e, consequentemente, da construção das zonas do modelo de perfil conceitual de morte, por meio da pesquisa empírica e das análises teóricas, a saber:

Naturalista: construída a partir da perspectiva teórica organicista da vida, ou seja, enquanto fenômeno resultante de uma disfunção orgânica e que, num momento ou noutro da vida, atingirá todos os seres humanos. Podemos observar a zona naturalista emergindo, por exemplo, nas posições dos autores de ciências biológicas e medicina. Weissmann (1889), por exemplo, traz à tona essa forma de pensar quando diz ser a morte resultado do envelhecimento orgânico de células e tecidos. Nos escritos médicos de Kübler-Ross (1998) e de Carrel (1950), a morte também é caracterizada como um fenômeno natural, condição de todo ser vivo. Da mesma forma, aquilo que estamos denominando zona naturalista pode ser percebida nos escritos sociológicos de Elias (2001) e Morin (2002), quando falam da condição natural da morte, chamando a atenção para a necessidade humana de, primeiro, acreditar na imortalidade da alma e, num segundo momento, negar ou ocultar sua existência.

Religiosa: identificada por meio do reconhecimento da mortalidade do corpo e, como contraponto, da ideia da imortalidade da alma, tendo sido sustentada, em termos filosóficos, nos escritos de Platão (2004) e Kierkegaard (2001). Na medicina, em Carrel (1950) encontramos indícios do tratamento da morte para além de um fenômeno natural, posto que o autor discute a crença humana na imortalidade da alma. Além disso, pudemos perceber, por meio de uma breve análise das diferentes doutrinas religiosas ${ }^{4}$, que a discussão sobre a morte centra-se, especialmente, no pós-morte, seja pela crença na ressurreição, na reencarnação ou no renascimento. Assim, temos, mesmo que com fundamentos diferentes, entre os sistemas religiosos, conceituações que se aproximam daquilo que denominamos, nesse estudo, percepções religiosas da morte.

Relacional: uma zona na qual estão formas de pensar que indicam aspectos sobre a relação do ser humano com a morte. É neste contexto que vemos, por um

${ }^{4}$ Budismo, Catolicismo, Espiritismo, Hinduísmo, Igreja Ortodoxa, Islamismo, Judaísmo e Protestantismo. 
lado, os medos, as angústias e a dificuldade humana de pensar e/ou corporificar sua própria morte como sendo os responsáveis pela sua ocultação, negação. Por outro lado, também são explicitadas na zona relacional visões da morte numa perspectiva da herança histórica e cultural. Ou seja, de que, independente da existência física, o ser humano se fará presente, entre os vivos, por sua história, suas obras. A zona relacional da morte é ratificada nos escritos sociológicos de Elias (2001) e Morin (2002), para quem a consciência da finitude da vida traz implicações históricas, culturais e sociais, e na medicina, quando Kübler-Ross (1998) chama a atenção para a naturalidade da morte e para a suposta dificuldade que o ser humano tem de lidar com o moribundo, com a morte e com o morrer. É, por fim, na psicologia e na psicanálise, em Fromm (1987) e Freud (1996), que encontramos os indícios que sustentam de forma mais contundente a conceituação de morte, na perspectiva de negação e/ou ocultação. Assim, a zona relacional resulta do conflito travado pela consciência humana a partir de dois elementos, quais sejam: o reconhecimento da morte como fenômeno que pode se manifestar a qualquer momento, interrompendo projetos e fazendo com que sobrevivam apenas as lembranças, as ações, a história e a necessidade que o ser humano tem de se munir de artefatos que o distanciem da sua condição de mortal.

Em termos empíricos, os dados coletados, por meio de questionários, tornaram possível a identificação de expressões típicas, associadas às zonas do modelo de perfil conceitual.

Em relação à zona naturalista, encontramos, em primeiro lugar, expressões que fazem referência a órgãos, células, metabolismo, respiração, composição química etc., atribuindo à morte a condição de fenômeno que resulta na cessação das funções vitais do organismo, como externado, por exemplo, na resposta a seguir: "Órgãos/células deixam de funcionar". Em segundo, foi possível identificar menções ao ciclo de vida, como percebemos na seguinte resposta: "Porque a morte é o último estágio pelo qual todo organismo vivo passa". Em terceiro, temos expressões que fazem referência aos seres vivos na sua generalidade, ou seja, "todos", "outros", como no exemplo: "Todos os seres passam por isso." Outra forma de falar é aquela que expressa a morte enquanto possibilidade ou capacidade de sucessão dos seres vivos, garantindo o equilíbrio natural. Como exemplo, temos a seguinte resposta: "Permite a sucessão dos seres e o equilibrio natural". Por fim, são apresentadas as expressões que fazem referência à morte como algo normal, parte da natureza humana, como nos exemplos: "É o normal", ou ainda, "Porque é a natureza da vida".

Em relação à zona religiosa, também encontramos um conjunto de modos de falar típicos. Em primeiro lugar, estão expressões que fazem menção à morte na perspectiva do "duplo", ou seja, à dualidade corpo/alma, à existência de outra vida, do pós-morte. São exemplos desses modos de expressão as seguintes 
respostas: "Começo de uma vida espiritual eterna"; "Espírito sai do corpo/ desencarnação da alma". Em segundo, temos expressões que fazem referência a "Deus", à "vontade divina" e expressões derivadas que fazem parte da linguagem de diferentes sistemas religiosos, como céu e inferno. São exemplos as respostas seguintes: "Só acontece para quem não tem Jesus no coração"; "Continuidade da vida no céu ou inferno". Em terceiro lugar, estão expressões que caracterizam a morte enquanto destino, cumprimento de uma missão. Entre os exemplos, citamos: "Quando a pessoa terminou de cumprir seu papel/missão nessa vida". Em quarto lugar, estão as passagens bíblicas, como, por exemplo: "[A morte é] libertação de uma prisão chamada vida".

Também no caso da zona relacional, foi possível a identificação de um conjunto de formas de falar típicas. Primeiramente, temos expressões que fazem menção à morte como fenômeno que provoca medo, angústia, expressando a dificuldade de aceitação, como por exemplo: " $A$ [morte é a] coisa mais terrivel do planeta". Depois, temos as expressões que traduzem a percepção da morte enquanto mistério, algo desconhecido, como no exemplo: "[A morte é] desconhecida por todos e idealizada por muitos". Em terceiro lugar, estão expressões que caracterizam a morte em decorrência de um enunciado específico, provocado, nesse caso, pelas questões $5 \mathrm{~b}$ e $5 \mathrm{c}$. Ao contrário dos exemplos anteriores, nos quais a morte era caracterizada por meio da utilização de uma linguagem social, nesse caso temos caracterizações da morte como parte de um gênero de discurso, em resposta a situações de comunicação específicas, quais sejam: Quais considerações você teceria, sobre a morte, diante de cada uma das notícias que seguem: (5b) Faleceu o pai, de 55 anos, de seu/sua melhor amigo(a) e (5c) Faleceu o irmão, de 26 anos, de seu/sua melhor amigo(a). São exemplos as seguintes respostas: "Poderia viver um pouco mais"; "Chegou na hora erra$d a$ ". Em quarto, estão expressões que apontam a morte como sendo resultado das escolhas, das ações humanas e que chamam a atenção para as implicações históricas e sociais do fenômeno. Essas expressões foram encontradas principalmente nas respostas das questões 1 e 4. É um exemplo: "Ficam lembranças, embora seja o fim de uma história elou de relações sociais".

\section{Modos de pensar e falar a morte: alguns resultados}

Nesta seção, optamos por apresentar apenas os resultados obtidos para o curso de ciências biológicas, que é responsável pela formação dos futuros profissionais, licenciados em ciências biológicas, que atuarão no Ensino de 
Ciências, anos finais do ensino fundamental e ensino médio. Em relação à questão 1 , a maior quantidade de respostas $(60 \%)$ foi pertinente à zona naturalista, e a menor, à zona relacional. Ou seja, para estes sujeitos, a morte é percebida como algo normal, natural, componente da vida humana. É importante notar que esta questão foi organizada com o intuito de suscitar a maior variedade possível de respostas, o que torna ainda mais relevante o fato de que, embora mais da metade das respostas se relacionarem à zona naturalista, 33,8\% foram vinculadas à zona religiosa, mostrando que a questão de fato suscitou uma diversidade de respostas.

No caso da questão 2, as respostas fornecidas pelos sujeitos do curso de ciências biológicas se alinharam com a zona naturalista, chegando a 94,7\%, enquanto que uma quantidade diminuta foi relacionada à zona religiosa e nenhuma resposta à zona relacional. Isso mostra que, num contexto de sala de aula, mobilizado na questão, os estudantes de ciências biológicas se inclinam na direção da zona naturalista, possivelmente por considerá-la mais aceitável no que tange ao conhecimento científico acadêmico. Na questão 3, também a maior incidência de respostas se situou na zona naturalista (74\%). Isso mostra que também numa situação cotidiana a maioria dos estudantes recorre ao modo de falar/pensar característico da zona naturalista. A maior incidência de respostas às questões 1,2 e 3 na zona naturalista nos remete a perceber que a morte, nesse caso, é percebida como característica dos vivos e, por conseguinte, chega como resultado de uma disfunção interna. Assim sendo, a morte parece estar sendo pensada como sendo "uma possibilidade real, não só para os outros, como para si mesmo." (KÜBLER-ROSS, 1998, p. 31).

No que diz respeito à condição da morte como algo definido por uma divindade, um ser superior, tal como colocado na questão 4, percebemos que $71,2 \%$ dos estudantes apresentaram respostas que correspondem à zona religiosa. Neste caso, a questão mobilizava um discurso de caráter religioso e, em contraste com o que foi observado num contexto de sala de aula e cotidiano, apareceu um modo de falar/pensar a morte como o fim da vida orgânica e o início de uma vida espiritual, bem como a ideia de que ela é resultado da "vontade divina". Contudo, foram também relativamente frequentes respostas alinhadas com os modos de pensar relacional e naturalista ( $12,3 \%$ das respostas, nos dois casos). Isso mostra a polissemia do conceito de morte e, mais do que isso, o valor pragmático de diferentes modos de pensá-lo, a depender do contexto discursivo, tal como capturado num modelo de perfil conceitual.

Na questão 5a, os estudantes de ciências biológicas se inclinaram, em sua maioria, para a zona naturalista $(94,5 \%)$, enquanto a zona relacional predominou nas questões 5 b e 5 c $(54,1 \%$ e $56,8 \%$, respectivamente). É curioso notar que, no caso de uma pessoa com mais idade, estes estudantes se sentiram mais 
à vontade para mostrar um compromisso com um modo de pensar naturalista do que no caso de pessoas com menos idade. Isso reflete uma percepção que, na maioria das vezes, é externada pelo ser humano, qual seja: de um lado, uma fácil acomodação/aceitação do desaparecimento de um idoso e, de outro, a difícil aceitação/acomodação da perda ou a dor da perda quando a "vítima" é um jovem. Isto posto, podemos refletir sobre o que segue: "outro velhinho querido, 92 anos, cego, surdo, todos os esfíncteres sem controle, numa cama - de repente um acontecimento feliz! Ah, com certeza fora seu anjo da guarda que punha um fim à sua miséria!" (ALVES, 2003, p. 3). Por outro lado, é necessária a consideração de que "é terrível quando pessoas morrem jovens, antes que tenham sido capazes de dar sentido às suas vidas e de experimentar suas alegrias." (ELIAS, 2001, p. 77). Estes são sentimentos que, em nosso entendimento, estão subjacentes às diferenças das respostas dadas pelos estudantes de ciências biológicas às questões $5 \mathrm{a}, 5 \mathrm{~b}$ e $5 \mathrm{c}$.

Dando sequência às análises, em termos de evolução das zonas, no Gráfico 1 percebemos que, no curso de ciências biológicas, a zona naturalista se manteve com frequência estável entre as respostas dos estudantes, com pequenas oscilações ao longo do primeiro $(55,2 \%)$, terceiro $(56,8 \%)$ e quinto períodos $(53,5 \%)$. A zona religiosa sofreu uma queda importante em sua frequência entre o primeiro e o terceiro períodos, com sua incidência passando de $27 \%$ para $18,3 \%$, com um aumento no quinto período $(22,5 \%)$ que não chegou a mostrar um retorno à frequência do começo do curso. A zona relacional, por fim, apresentou aumento contínuo, partindo de $15,2 \%$ no primeiro período e chegando a $24 \%$ no quinto. De modo geral, foi possível perceber, ao longo dos períodos do curso de ciências biológicas, que o aumento da zona relacional foi correspondente à diminuição da religiosa.

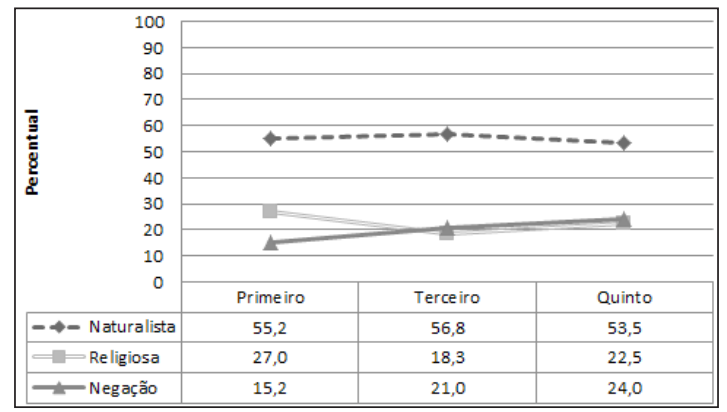

Gráfico 1 - Evolução das zonas do Perfil Conceitual de Morte, no curso de Ciências Biológicas. 
Analisando os dados de ciências biológicas ou, ainda, os dados dos diferentes cursos em seu conjunto, não foi possível notar, ao longo dos períodos dos vários cursos investigados, uma evolução de uma zona para outra, considerando o modelo de perfil conceitual que construímos. Os dados ratificaram nossa suspeita inicial de que o conceito de morte não tem sido abordado no contexto acadêmico/escolar, o que nos permite afirmar, por consequência, que o conceito de morte não é um conceito escolarizado. Ou seja, a universidade/escola tem feito pouco, ou quase nada, em termos de abordagem pedagógica sobre o tema e, por isso, não favorece nem o enriquecimento do perfil conceitual dos estudantes, mediante a introdução de novas zonas, nem uma tomada de consciência em relação aos modos de pensar correspondentes a cada zona.

Reverter esse cenário e promover a escolarização do tema, no âmbito da universidade, se faz importante, a nosso ver, se considerarmos o locus de estudo dos cursos envolvidos nesse estudo, a saber: ciências biológicas: seres vivos; medicina: ser humano; ciências sociais: mundo humano e seus aspectos sociais, e pedagogia: processos educativos. Da mesma forma, temos que considerar que o conteúdo abordado na disciplina de ciências, na sétima série (oitavo ano), é basicamente anatomia e fisiologia humana. Uma breve análise do exposto nos remete a considerar que ao estudar os seres vivos, de forma geral, e os seres humanos, de forma mais específica, torna-se indispensável que seja contemplada a temática morte, posto que ela se configura como fenômeno que coloca "um fim na vida", ou seja, por seu intermédio deixam de existir os seres vivos e/ou os seres humanos. Pensamos ainda que serão os processos educativos desenvolvidos pelos licenciados em ciências biológicas e pedagogia os responsáveis pela promoção da escolarização do tema, nos distintos níveis de ensino e, por consequência, pela diminuição da tensão entre os vivos e os mortos e, especialmente, da dificuldade que o homem possui para lidar com este fenômeno. Assim, as práticas pedagógicas desenvolvidas nas salas de aula de ciências precisarão fortalecer as discussões da morte a partir dos elementos que constituem a zona naturalista, posto que nela alocamos elementos específicos do discurso da ciência natural.

\section{Escolarização do conceito de morte: das caracterizações do ciclo de vida ao desenvolvimento da sequência de ensino}

Após a identificação das zonas do modelo de Perfil Conceitual de Morte e ante a percepção de não evolução do conceito de morte e de sua consequente não escolarização, passamos à identificação das caracterizações de ciclo de vida 
e ao planejamento da sequência de ensino sobre ciclo de vida como alternativa de escolarização do conceito de morte.

Inicialmente, permitimo-nos chamar a atenção para o fato de que fizemos uma opção por definir ciclo de vida, como característica de todo ser vivo, como sendo composto obrigatoriamente pelo nascer e morrer, uma vez que, a nosso ver, a complexidade do ciclo de vida não apresenta variação apenas de espécie para espécie, mas também de indivíduo para indivíduo, dentro de uma mesma espécie. ${ }^{5}$ A análise dos dados coletados, junto aos 361 sujeitos de pesquisa, por meio da situação problema seis, "Considerando o que você aprendeu, no ensino fundamental, caracterize CICLO DE VIDA", nos permitiu identificar duas caracterizações de ciclo de vida que denominaremos de Clássica e Alternativa. Na primeira, agrupamos todas as respostas que conceituaram ciclo de vida como sendo constituído obrigatoriamente pelo nascer, crescer, se reproduzir, envelhecer e morrer. Na segunda, alocamos respostas que consideraram a possibilidade da morte se efetivar antes da completude do ciclo, ou seja, antes do envelhecimento.

Esclarecemos também que a abordagem nas duas turmas de 7. a série contemplava, em um primeiro momento, as atividades comumente propostas pela professora quando do desenvolvimento de um trabalho sobre ciclo de vida, ou seja, o desenvolvimento de aulas expositivas dialogadas, por meio das quais os estudantes entraram em contato com a caracterização do ciclo de vida completo: nascer, crescer, se reproduzir, envelhecer e morrer. Num segundo momento, propusemos uma atividade que foi realizada somente pelos estudantes da 7. a série A e, nesse caso, promovemos a discussão sobre "Outras possibilidades de constituição do ciclo de vida" e sobre "o nascer e o morrer", etapas que constituem, a nosso ver, obrigatoriamente, o ciclo de vida de todos os seres vivos. Para o desenvolvimento da atividade, a turma foi organizada em cinco grupos e cada grupo recebeu uma folha de papel, madeira, pincel atômico, cola, tesoura e revistas para recorte. Na sequência, a professora explicou à turma que a atividade exigia a construção de um painel com figuras que seriam retiradas das revistas e relatou aos estudantes a seguinte situação: "Na aula anterior, estudamos o Ciclo de Vida. Falávamos que ele é composto pelo nascer, crescer, se reproduzir, envelhecer e morrer. Hoje gostaria que vocês discutissem, com os colegas do grupo, sobre outras possibilidades de constituição do Ciclo de Vida." Continuou ratificando a orientação inicial de que deveria representar as possibilidades pensadas, por meio da organização de um painel com recortes

${ }^{5}$ Tal opção se deu para que pudéssemos considerar a abordagem da unidade de acordo com o que está posto nas propostas curriculares oficiais brasileiras e que refletem a abordagem pedagógica (embora sujeita a análises e críticas) desenvolvida em sala de aula. 
de revista. A turma prontamente iniciou a atividade. Em poucos minutos, os diferentes grupos discutiam outras possibilidades de constituição do ciclo de vida e as representavam utilizando as figuras. Relataremos, neste texto, apenas as tarefas realizadas pelos grupos 01 e 04 .

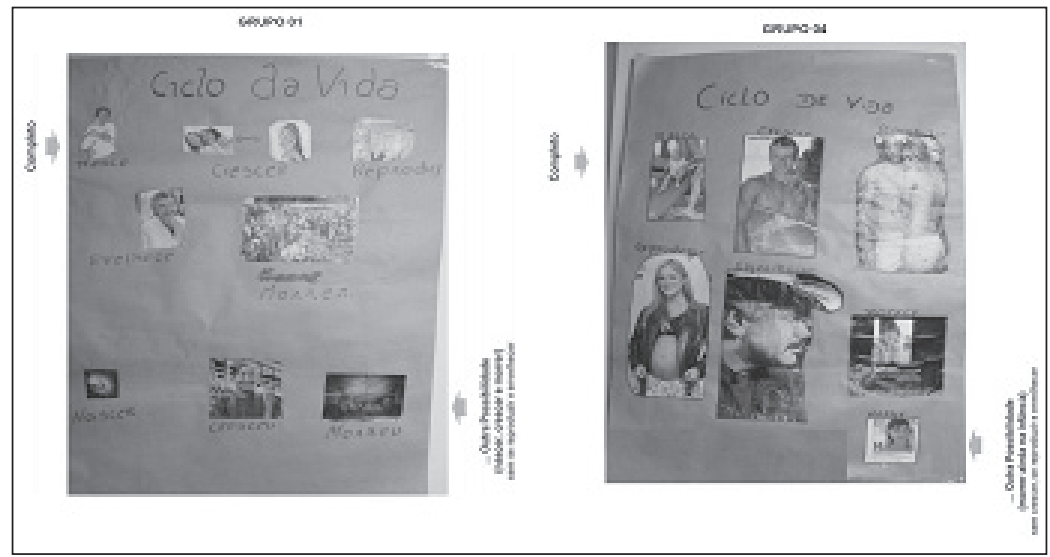

Figura 1 - Painéis dos grupos 01 e 04 - "Outras possibilidades do ciclo de vida".

O grupo 01 (Figura 1) demonstrou, por meio das figuras, um ciclo de vida composto pelo nascer, crescer e morrer. Temos aqui a apresentação de uma "Outra possibilidade de ciclo de vida" que nos remete à reflexão acerca da efetivação da morte antes do cumprimento das fases de reprodução e envelhecimento. No painel do grupo 04 (Figura 1), no entanto, tivemos como "Outra possibilidade de ciclo de vida" aquela que indica a morte quando ainda se é criança. Neste caso, o grupo utilizou figuras de uma menina que morreu com seis anos para chamar a atenção dos colegas sobre a possibilidade de a morte ocorrer ainda quando se está na infância. Em ambos os painéis, o ciclo de vida representado vai ao encontro daquele que defendemos constituir a melhor abordagem da temática, posto que o nascer e o morrer são de fato as fases garantidas a todos os seres vivos. Esse dado pode estar vinculado, a nosso ver, à abordagem pedagógica do ciclo de vida desenvolvida na turma, já que os estudantes puderam refletir sobre alternativas várias de constituição do ciclo de vida e sobre a possibilidade de a morte se manifestar em um sujeito que não viveu o "ciclo completo".

Buscamos escolarizar o conceito de morte por meio do desenvolvimento de uma prática pedagógica que reconheceu a opinião singular de cada estudante e, por isso, objetivou contemplar as diferentes ideias que emergiram quando da abordagem do conceito em sala de aula. Da mesma forma, buscamos com a atividade não perder de vista a possibilidade da discussão, da reflexão conjunta, do 
reconhecimento da existência de vários pontos de vista e do confronto/encontro de ideias como alternativa para que sejam abarcadas novas ideias apresentadas pelo professor ou pelos colegas. E é esse processo de relação, entrelaçamento e complementação que constitui, segundo Bakhtin (2003), o encontro dialógico de duas culturas, onde ocorre o enriquecimento mútuo, a aprendizagem, a construção de novos conceitos científicos e/ou a ampliação de conceitos já existentes. Nesse caso, estamos considerando a cultura científica escolar, da qual os professores são os representantes, e a cultura cotidiana, representada tanto pelos professores como pelos estudantes.

Nesta perspectiva, aos professores é atribuída a responsabilidade de considerar que, ao falar, deve levar em conta o fundo aperceptível da percepção do discurso pelo destinatário: até que ponto ele está a par da situação; suas concepções e convicções; seus preconceitos; suas simpatias e antipatias - tudo isso irá determinar a ativa compreensão responsiva do enunciado (BAKHTIN, 2003). Aos estudantes compete, no entanto, a percepção de que, “aprender a falar significa aprender a construir enunciados (porque falamos por enunciados e não por orações isoladas e, evidentemente, não por palavras isoladas). [...] Nós aprendemos a moldar o nosso discurso, [...] quando ouvimos o discurso alheio." (BAKHTIN, 2003, p. 283). Embora sendo detentores de papéis específicos, professores e estudantes participam conjuntamente, em sala de aula, de um processo dialógico onde, por meio do discurso, são estabelecidas constantes relações entre o enunciado principal e outros enunciados.

Por fim, aplicamos o questionário (pós-teste) em ambas as turmas, para compararmos os dados obtidos e as possíveis alterações nos modos de falar/ pensar utilizados pelos estudantes para conceituar ciclo de vida e morte, antes e depois da abordagem pedagógica.

A análise conjunta dos gráficos 2 e 3 nos permite inferir que por ocasião do pós-teste, realizado após a abordagem pedagógica do ciclo de vida, ocorreu, na 7. ${ }^{a}$ série $A$, o aumento na incidência da categoria alternativa. Ou seja, 29,1\% dos estudantes, após realizar a atividade de construção do painel apresentando

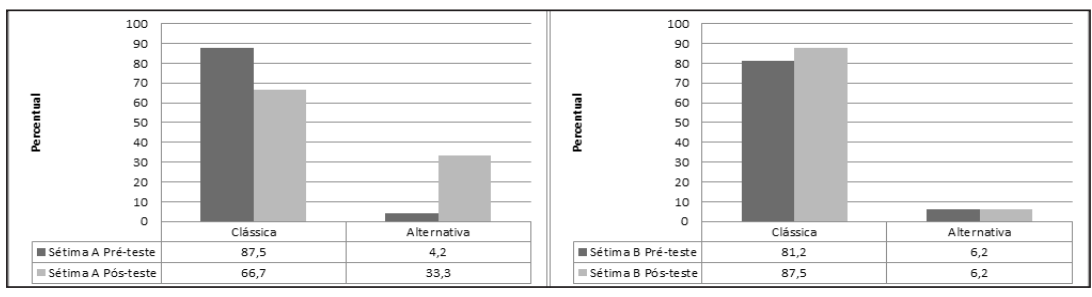

Gráfico 2 - Caracterizações de Ciclo de Vida, Gráfico 3 - Caracterizações de Ciclo de Vida, do pré-teste ao pós-teste, $7 .^{\text {a }}$ Série A. do pré-teste ao pós-teste, 7. ${ }^{a}$ Série B. 
"Outra possibilidade de constituição do ciclo de vida", passaram a utilizar uma concepção alternativa para caracterizá-lo. Esse não foi, entretanto, o cenário encontrado entre os estudantes da 7. a série $\mathrm{B}$, posto que a categoria clássica apresentou aumento de percentual, do pré ao pós-teste, e a categoria alternativa se manteve inalterada.

Nos gráficos 4 e 5, os dados nos possibilitam comparar a evolução das zonas do Perfil Conceitual de Morte, do pré-teste ao pós-teste, nas 7 as séries $^{\circ}$ A e B. A análise dos dados aponta que, por ocasião do pós-teste, ocorreu na 7. a série A um aumento na incidência da zona naturalista e uma queda na zona religiosa. Analisando os dados, percebemos que, na 7. ${ }^{a}$ série $\mathrm{B}$, a zona naturalista apresentou leve aumento, enquanto as zonas religiosa e relacional apresentaram leve queda. Os dados da 7. a série B precisam ser considerados especialmente porque indicam baixa oscilação nos resultados e porque nesta turma a abordagem pedagógica promoveu aos estudantes o acesso ao discurso científico sobre o ciclo de vida, mas não a realização da atividade em grupo, ou seja, não vivenciaram a possibilidade de refletir sobre "Outras possibilidades de constituição do ciclo de vida".

Assim, podemos inferir que, por ocasião da abordagem pedagógica, os estudantes tiveram acesso ao discurso científico sobre o ciclo de vida e sobre a morte, o que pode ter favorecido o aparecimento, no pós-teste, de modos de falar específicos de sala de aula e, por consequência, um maior número de sujeitos utilizando, em suas respostas, argumentos naturalistas/biológicos para conceituar a morte. Argumentos esses que são os que mais se aproximam do discurso da ciência. Os dados nos permitem perceber também que a abordagem pedagógica desenvolvida sobre ciclo vida, na 7. a série A, promoveu mudanças mais expressivas nas formas de pensar e nos modos de falar desses estudantes.

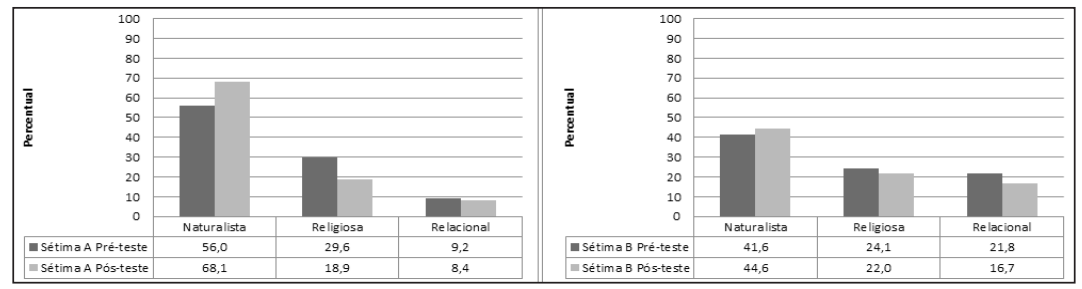

Gráfico 4 - Evolução das zonas do Perfil Conceitual de Morte, do pré-teste ao pós-teste, $7 .^{\text {a }}$ Série A.
Gráfico 5 - Evolução das zonas do Perfil Conceitual de Morte, do pré-teste ao pós-teste, $7 .^{\text {a }}$ Série B. 


\section{Considerações finais}

O presente estudo teve como resultado a proposição de um modelo de perfil conceitual de morte, contendo três zonas, quais sejam: (a) naturalista: a morte se apresenta como um fenômeno orgânico, inerente à vida; (b) religiosa: a morte indica o fim da vida terrena e, por consequência, o início de uma vida eterna, podendo ser também entendida como resultado da "vontade divina", e (c) relacional: comporta aspectos concernentes às relações entre o ser humano e a morte, com suas implicações históricas, culturais, sociais, bem como considera sua ocultação e não aceitação.

Os dados apontam que a morte, quando considerada de forma geral, foi conceituada como sendo um fenômeno natural, biológico, inerente à condição humana. No entanto, quando pensada em termos específicos, como, por exemplo, fazendo referência a um sujeito com papel social e/ou idade específica, esse cenário sofre uma alteração e a zona relacional passa a assumir maior expressividade. Da mesma forma, a análise dos dados denuncia a não evolução de uma zona, o que nos permite afirmar que o conceito não é escolarizado.

Assim, as salas de aula, especialmente de ciências, precisam se tornar espaços privilegiados para a escolarização do conceito de morte e, para tanto, as práticas pedagógicas desenvolvidas precisam reconhecer que, ao considerar as zonas que constituem um perfil conceitual, tem que se considerar a diversidade de formas de pensar e falar que podem emergir para conceituar um único conceito. Precisamos, pois, admitir a diversidade e a heterogeneidade de abordagens que deverão passar a compor os processos de ensinar e de aprender, sem perder de vista as especificidades de cada área do conhecimento e sem superficializar as práticas pedagógicas e o processo de construção do conhecimento. Tratar do conceito de morte se justifica se levarmos em conta duas importantes questões: (a) o fato de estarmos nos referindo a um conceito polêmico e multicultural e (b) a consideração de que os dados coletados neste estudo são forte indício da não escolarização do conceito. Da mesma forma, destaca-se que, em termos de ciclo de vida, a importância se vê ratificada devido à especificidade/singularidade da constituição deste em cada indivíduo e, em termos de morte, pela sua oposição à vida, condição básica de todo ser vivo e objeto central de estudo da biologia/ciências.

Chamamos a atenção para o fato de que temos, a exemplo do observado na 7. ${ }^{a}$ série $\mathrm{B}$, comumente nas salas de ciências, como proposta de ensino para o ciclo de vida e a morte, uma abordagem pedagógica que se limita à mera apresentação de informações triviais ${ }^{6}$ aos estudantes. Ou seja, com muita frequência

${ }^{6}$ Como, por exemplo, todo ser vivo tem ciclo de vida, ou seja, nasce, cresce, se reproduz, envelhece e morre. 
são desconsideradas as curiosidades e são limitadas as discussões e interações que poderiam contemplar os diferentes pontos de vista que circulam em sala de aula e, da mesma forma, se atribui ênfase excessiva ao discurso da ciência, o que dificulta a evolução conceitual, tanto em termos da conceituação do ciclo de vida como em termos de evolução das zonas do perfil conceitual de morte.

Por outro lado, um indício do sucesso da atividade desenvolvida na $7 .{ }^{\mathrm{a}}$ série $\mathrm{A}$, onde os estudantes foram chamados a construir e apresentar, por meio da organização de painéis com figuras, "Outras possibilidades de constituição do ciclo de vida", foi a mudança que se fez presente nas respostas atribuídas para a conceituação do ciclo de vida, se compararmos os dados do pré com os dados do pós-teste. São exemplos de respostas que provocaram a oscilação nos dados as seguintes: Pré-teste: "Nascer, crescer, se reproduzir, envelhecer e morrer" e Pós-teste: "Etapas que formam a vida de um ser. Nem todos vivem o Ciclo completo." (Q412P7CEF) Da mesma forma, são respostas que ratificam a evolução e, consequentemente, a mudança de zona do perfil conceitual de morte as atribuídas para a questão sobre o que é morte: Pré-teste: "Morte é para mim algo que acontece com quem vive muito e fica velho. É a passagem para outra vida" e Pós-teste: "É uma fase da vida. O fim da vida." (Q418P7CEF ).

\section{REFERÊNCIAS}

ALVES, R. Sobre a morte e o morrer. São Paulo: Sinapse, 2003.

BAKHTIN, M. Estética da criação verbal. Trad. Paulo Bezerra. Rio de Janeiro: Forense Universitária, 2003.

CARREL, A. O homem perante a vida. Trad. Cruz Malpique. Porto: Educação Nacional, 1950.

ELIAS, N. A solidão dos moribundos. Trad. Plínio Dentzien. Rio de Janeiro: Zahar, 2001.

FREUD, S. Além do princípio do prazer. In: Edição standard brasileira das obras psicológicas completas de Sigmund Freud. v. XVIII. Rio de Janeiro: Imago, 1996.

FROMM, E. Ter ou ser? 4. ed. Trad. Nathanael C. Caixeiro. Rio de Janeiro: LCT, 1987. HOLQUIST, M. The dialogic imagination. Austin: University of Texas Press, 1981.

KIERKEGAARD, S. O desespero humano. Martin Claret: São Paulo, 2001.

KÜBLER-ROSS, E E. Sobre a morte e o morrer. Trad. Paulo Menezes. São Paulo: Martins Fontes, 1998. 
MAYR, E. Isto é biologia: a ciência do mundo vivo. Trad. Cláudio Ângelo. São Paulo: Companhia das Letras, 2008.

MORIN, E. O método 2: a vida da vida. Trad. Marina Lobo. Porto Alegre: Sulina, 2002. MORTIMER, E. F. Construtivismo, mudança conceitual e o ensino de ciências: para onde vamos? In: UFRS, v. 1, n. 1, p. 20-39, 1996. Revista Investigações em Ensino de Ciências, Porto Alegre, . Perfil conceptual: formas de pensar y hablar en las clases de ciencias. Infancia y Aprendizaje, v. 24, n. 4, p. 475-490, 2001.

PLATÃO. Fédon: diálogo sobre a imortalidade da alma. Trad. Heloisa da Graça Burati. São Paulo: Reedel, 2004.

WEISMANN, A. Life and death. In: . Essays upon heredity and kindred biological problems. Oxford: At The Clarendon Press, 1889.

Texto recebido em 15 de novembro de 2011.

Texto aprovado em 08 de dezembro de 2011. 